\title{
A CIENCIA E OS CIENTISTAS NA OBRA DE ALDOUS HUXLEY
}

Olga Lana Cardoso

Parece paradoxal que Aldous Huxley, que pensara em dedicar-se à ciência, faça a ela tantas restrições. É conhecido o seu interesse por problemas científicos e as suas inúmeras referências ao fato de não ter podido devotar-se à ciência por causa de uma doença nos olhos, que quase o deixou cego:: ( "my scientific training which my blindness made me miss.") Vejamos alguns aspectos da formação do escritor.

Aldous Leonard Huxley (1894-1963), muito mais conhecido por seus romances, produziu também poemas e ensaios, nos quais abordou os mais variados assuntos. E inegável a diversidade de sua obra e a complexidade do autor. É vasía a obra crítica em torno de seus livros, na qual vamos encontrar as mais diversas opiniões. Os críticos, porém, são unânimes em afirmar a sua contribuição à literatura do século XX. A sua obra oferece uma vasta possibilidade de exploração, nos mais diversos campos de estudo. Ele escreveu ou divagou sobre uma ampla gama de temas, e o ambiente cultural, em que teve a sorte de nascer e viver, deve ter contribuído para que ele tusse o "homem de conhecimento enciclopédico" que foi. E oportuno lembrar o seu interesse, igualmente grande, pelas artes e ciễncias e a sua descendência de Thomas Henry Huxley, o biólogo, e Matthew Arnold, o literato, fato tão comentado por quantos escreveram sobre ele.

Já tivemos oportunidade de explorar alhures o elemento do absurdo nos seus quatro primeiros romances: Crome Yellow (1921), Antic Hay (1923), Those Barren Leaves (1925) e Point Counter Point (1928) Estas obras nos dão a conhecer um dos aspectos da visão de mundo do autor e a sua desilusão com a sociedade, cujos valores espirituais ele tanto questionou. Outros aspectos poderiam ter sido explorados. Milton Birnbaum, na obra Aldous Huxley's Quest for Values (1971), sugere que aqueles mesmos romances monstram uma total ausência de valores tradicionais, como o amor, a religião, e a vida em família na geração de após a Primeira Grande Guerra, assunto digno de ser estudado em maior profundidade. Haverá, na certa, na vasta obra 
huxleyana, dezenas de temas que dariam margem a interessantes estudos. Nossa curiosidade, porém, levou--nos a buscar as possíveis razões que levaram o autor a criar homens de ciência tão consideráveis, quando ele dizia que se the fosse dada uma opsão, preferiria ser $\mathrm{Fa}-$ lady (1) a ser Shakespeare. (Along the Road, 1925)

Quanto ao fato de Huxley ter--se envolvido com a ciência antes de se voltar para as letras, o seu irmão Julian, na obra Aldous Huxley: A Memorial Volume (1966), diz que todas as referências feitas por Aldous Huxley a fatos científicos, nos romances, são produtos de suas pesquisas. Diz que ele era grande estudioso, e ambos discutiam prolongadas horas sobre assuntos daquela natureza, sempre com mútuo proveito. Julian deixa claro que as citações feitas por Aldous, em seus livros, não eram ditadas pelo irmão, como insinuam alguns biógrafos. Ele faz questão de acrescentar que esse interesse pelas coisas já vinha da sua infância, quando "he spent a good deal of time just sitting, quietiy, contemplating the strangeness of things." (p. 21-25) No livro mencionado, uma verdadeira coletânea de impressões sobre Huxley, feitas por parentes e amigos que conviveram com ele, temos afirmações interessantes para o assunto em pauta. Dignos de nota são estas do próprio Julian, que diz ainda, à página 23: "He was always concerned with perfection of achievement and discovery, not only in the arts but also in the science." Gervas Huxley, seu primo, fala de seu grande interesse pela história natural (p. 58), e Denis Gabor, à página 68 , diz textualmente: "He was a consummate literary artist with a profound understanding of science." Todas essas vozes, testemunhas valiosas sobre a formação do autor, comprovam o seu vasto conhecimento, que pode ser entrevisto, realmente, ao longo de toda a sua obra. Esse interesse pelos mais diversos temas não esmoreceu com o passar dos anos. Pelo contrário, foi amadurecendo à medida que o tempo passava. Huxley se assemelha ao homem renascentista, de conhecimento ilimitado. Este homem de imensa leitura buscava a perfeição na cultura das artes e das ciências .

Suas obras deixam entrever uma esperança de que o mundo pode melhorar, mas, para isso, é preciso começar pela recuperação individual dos seres humanos. ("There's just one corner of the universe you can be certain of improving, and that's your own self. " - Time Must

(1) Michael Faraday (1791-1867), cientista inglês nascido em Surrey. Como Huxley, Faraday era leitor assíduo da Enciclopédia Britânica, na qual diz ter adquirido as primeiras noções sobre eletricidade, campo em que se destacou. Faraday teve a oportunidade de ser um homem rico e foi levado a optar entre tratar de negócios e ganhar muito dinheiro, ou dedicar-se à ciência. Prefe-iu a última alternativa, e morreu tão pobre quanto nasceu. 
Have a Stop, 1945, p. 76) Ele parecia perplexo diante das loucuras dos homens, e afirma em Point Counter, Point, por exemplo, através de uma personagem criada à sua imagem e um dos seus porta-vozes, que é mais fcil apreender o que se relaciona com sociologia e metafísica do que conhecer os seus semelhantes. Em outras obras, personagens dizem que é mais fácil viver no mundo das idéias que no mundo dos homens (Denis, Crome Yellow; P Quarles, Point Counter Point); que haveria de chegar o tempo em que as máquinas substituiriam a "intrusão humana" (Wimbush, Crome Yellow); que a humanidade não é nada mais que um bando desprezível de animais (Coleman, Antic Hay); prefere a solidão ao contato humano. O próprio Huxley disse, certa feita, que o fato de não enxergar bem lhe dava a vantagem de não distinguir seres humanos a certa distância. A sua impressão sobre o ser humano talvez seja uma das razões que o levaram a criar personagens ridículas; provavelmente, a sua impressão sobre a má aplicação da ciência levou-o a criar cientistas estranhos e desajustados.

Depois de seu testemunho sobre o homem de após-guerra, demonstrado, plenamente, nas obras da década de vinte, ele causou impacto com o livro Brave New World, em 1932, quando criou verdadeiros robôs, antômatos, produtos engarrafados e rotulados, de acordo com a necessidade da sociedade criada. A ciência é que tornou possível a produção em massa de seres sem noção de família, sociedade, vida em comum, ajuda ao próximo. Aquela sociedade, cheia de normas e códigos, não permite o isolamento do homem e, paradoxalmente, leva-o a uma extrema solidão, que nem mesmo a droga "soma" consegue curar completamente. "O homem foi destruído pela ciência"

Parece que o homem ideal para Huxley, segundo a sua personagem Mark Rampion, de Point Counter Point, é um homem equilibrado, longe de perfeito, mas tendo instinto, corpo, espírito, consciência. Parece, também, que as suas personagens que, por sinal, são em vasto número, não se aproximam muito do que ele considera um tipo ideal, isto é, um misto de "anjo e diabo" São sempre uma coisa ou outra, ou só corpo ou só espírito e, talvez, por essa razão, se sintam desajustadas no mundo. Para ter um pouco de ajustamento é preciso recorrer a drogas, e para não ser muito infeliz é preciso buscar um escape de qualquer espécie. O intelectual, personagem aundante dentro de sua obra, é um homem que busca a fuga nos livros. Embora com bastante potencial para se adaptar à sociedade, não o consegue. Os seus intelectuais e cientistas são, em geral, imatıos, cheios de problemas, e não têm condições nem mesmo para enfrentar uma vida a dois. Como em Brave New World "everyone belongs to everyone else" (p. 69), sem a mínima possibilidade de uma vida normal em comum. Huxley parece não ter tido grande 
simpatia para com essas estranhas criaturas que criou, e isso pode ser dito a respeito de toda a sua obra de ficção, de Crome Yellow a Island, isto é, de 1921 a 1962 . Personagens comicas despertam a simpatia dos leitores, que riem de suas desgraças porque não se identificam com as vítimas. A sua veia cômica e satírica é vista através de quase toda a sua obra romanesca. Com essa afirmação não queremos dizer, absolutamente, que Huxley foi um autor que se manteve fiel a um estilo, a uma criação literária. Ele foi um escritor que primou, exatamente, pela variedade de estrutura, tom e estilo, mas, que se manteve imutável na maneira de encarar o homem. O homem excêntrico ,produto da Primeira Grande Guerra, ainda aparece com muitos traços semelhantes aos daquele que viveu os problemas da Segunda Guerra e o que enfrentou uma terceira - uma Guerra Atômica — por ele imaginada.

Huxley, no capítulo VIII da obra The Perennial Philosophy (1945), abordando o tema de como classificar pessoas, mostra a relação entre a constituição individual do homem e o seu temperamertto. Menciona várias tentativas feitas, no espaço de vários séculos, para chegar a um sistema de classificação das diîerenças humanas. Entre os vários exemplos citados, ele se detém num sistema que considera "mais compreensivo e mais adequado" e que foi elaborado pelo cientista americano William Sheldon" (2) e seus colaboradores. Milton Birnbaum, na obra já mencionada, dedica um capítulo (Huxley's Character Types) ao sistema Sheldoniano, ao qual ele diz ter feito sua própria adaptação, para analisar as personagens de Huxley Ele nos mostra que, embora muitas delas tivessem sido criadas antes de 19401942 , quando essa teoria apareceu, encaixam-se muito bem na classificação de Sheldon, o que não é nenhuma surpresa, porque é comum a prática preceder a teoria.

Concordamos com Milton Birnbaum quando diz que muitas das personagens huxleyanas se enquadram no sistema de Sheldon. Segundo essa teoria, uma pessoa é "uma mistura, em proporções variáveis, de três componentes físicos e três componentes psicológicos intimamente relacionados" Sheldon chama de "'endomorphy", "mesomorphy" e "ectomorphy" aos três componentes físicos. A cada uma dessas categorias físicas corresponde um padrāo de temperamento, a que Sheldon denomina de "viscerotonic", "somatotonic" e "cerobrotonic", respectivamente. O "endomorph", cuja característica física é a gordura, for-

(2) William Herbert Sheldon (1899) é o cientista norte americano que iniciou, em 1940, uma nova fase de estudos da biotipologia. Segundo este pesquisador, a morfologia corporal depende de vários fatores que atuam de modo diferente em cada organismo. Ele relaciona a constituição física dos indivíduos com seu comportamento. E autor da obra Atlas of Men, publicada em 1954. 
ma roliça, abdômen volumoso, corresponde ao "viscerotonic" isto é, aquele que come bem, gosta de conforto, prazeres e de companhia. O "mesomorph", cujo traço físico predominante é uma forte estrutura muscular, angulosidade dos contornos, é "somatotonic", isto é, gosta de ação, de perigo e de controlar a vida dos outros. O "ectomorph", caracterizado pela fraqueza e pela alta sensibilidade nervosa, corresponde ao "cerebrotonic", que prefere um mundo interior e privado, pois é inadaptável às injunções. O "cerebrotonic" é, pois essa espécie de personagem que vive num "plano intelectual" e que gosta de isolar-se da vida comum. Sente-se bem no "mundo das idéias", e Huxley é famoso por escrever esse tipo de romance - de idéias. Essas personagens vivem bem entre os livros, as suas telas de pintura, os seus estúdios de trabalho, mas não conseguem conviver, normalmente, com outros seres humanos. Os cientistas se sentem à vontade entre os animais de suas experiências, parecem compreender muito bem todas as suas reações; eles estão familiarizados com os tubos de ensaios, as pesquisas, mas são frustados na vida cotidiana. Lembremo-nos de que Huxley não é dado a grandes descrições físicas de suas personagens e que, portanto, se aplicarmos o sistema sheldoniano para classificá-las, temos de levar em conta muito mais os fatores psicológicos que os físicos. Convém lembrar, também, o que Milton Birnbaum salienta na sua obra, isto é, que Huxley acredita que o temperamento dos indivíduos seria variável, porque dependia muito da vontade livre de cada um. Assim, embora ele elogie a classificação de Sheldon e nós vejamos muitos pontos comuns entre ambos, temos que concordar que aquela classificação, que é científica, passa a ser ética, com Huvley. Em Island (1962), a educação em Pala (o lugar utópico) leva em consideração as diferenças individuais. Conscientes da diversidade humana e das fortes tendências para determinados temperamentos, os encarregados da educação reúnem grupos pequenos de temperamentos iguais. Vão aumentando-os com a adição de uma ou duas pessoas com temperamentos opostos. E é assim que eles conseguem superar os problemas e diminuir os polos extremos. Vemos Huxley pondo em prática as suas idéias a respeito de temperamento, livre arbítrio e uma educação adequada. (p. 213-214)

Voltando ao problema em foco, é válido lembrar, novamente, que Huxley pode ser, realmente, considerado tanto homem de arte, como homem de ciência. Alguns críticos tentam explicar a posição do autor . Para um deles (M. Birnbaum), ao abordar o assunto Faraday ou Shakespeare, diz que um literato é olhado com curiosidade, é esperado em sociedade muito mais que um cientista. Expõe, assim, a razão por que, para Huxley, seria melhor ser Faraday. Essa explicação, pouco convincentte, leva em conta o temperamento do escritor que, apesar de ser um tanto introspectivo, não deixou de frequientar a vila de Garsing- 
ton e participar de uma vida social intensa. (Naomi Mitchison, Aldous Huxley: A Memorial Volume, p. 83) Na sua ânsia de explicar a posição de Huxley, M. Birnbaum acrescenta, ainda, que "o artista trata primordialmente de emoções humanas e o cientísta de fenômenos não humanos." (Op. cit., p. 140) Nova tentativa de explicar a preferência, tendo em vista, agora, o estilo do escritor.

Não podemos ignorar o próprio autor e as suas reações quanto ao assuntios em toco. Embora ele nấo nos forneça a sua propria versão, à guisa de explicação, temos de considerar que, desde o início de sua carreira, ele vê a ciência como a grande causadora do desaparecimento de valores dos homens e da civilização. (Jesting Pilate, 1926.) Parece culpar a ciência por afastar os homens da religião, tornando-os mais materialistas e preocupados com o avanço tecnológico (Olive Tree, 1936) "A ciência não é capaz de explicar as complexidades da realidade porque ela não é capaz de compreendê-las" A ciência não ajudou o homem em nada para encontrar um meio mais adequado para viver uma vida equilibrada. A ciência, tão avançada, parece ter feito cientistas swiftianos (é inegável a influência de Swift sobre Huxley), que dedicam anos a fio de sua vida aos estudos de como amadurecer frutos em qualquer estação do ano (p. 195), como tirar raio de sol de pepinos (p. 197), como reduzir excremento humano ao aumento natural (p. 197), mas moram todos em casas em ruinas e sem e rto que comer. (Swift, Gulliver's Travels, 1726) Quais são as vantagens empíricas dessas pesquisas científicas absurdas? Quais os pontos positivos que elas trazem para a humanidade? Nós sabemos, pelas própria palavras de Huxley, em ensaios, que era esta a sua preocupação com relação à ciência. (What Can the Scientist Do?) Os cientistas huxleyanos não vão tão longe quanto os de Swift, mas também dedicam horas e horas aos estudos, enclausurados nos seus laboratórios. Um deles é capaz de transplantar caudas de lagartos em diferentes partes do corpo (Point Counter Point); outro é capaz de coletar suor para estudos profundos (Antic Hay); outro estuda macacos e carpas e como prolongar a vida humana e a plena atividade sexual (After Many a Summer, 1936); outro pesquisa a bomba atômica e até recebe o Prêmio Nobel pelas suas notáveis qualidades como físico (The Genius and the Golddess, 1955). Todos são, no entanto, incapazes de melhorar a própria vida ou de encontrar meios para viver mais adequadamente. A ciência está totalmente divorciada do lado prátic o da vida, e os cientistas, distantes da realidade que os rodeia, não procuram adaptar os padrões de vida ao mundo em que vivem.

A ciência está sendo usada contra o próprio homem; ela é culpada dos grandes males do mundo. Huxley cita, em obras de ficção e não- 
ficção, alguns males; a ciência não muda os indivíduos, pelo contrário, el faz com que os homens se tornem medíocres, e que percam seus empregos. (Science, Liberty and Peace, 1946) A ciência é a maior causadora das grandes guerras e, por conseguinte, da perda de liberdade individual do homem. O homem teme o seu semelhante e vive, mesmo em tempos de paz, uma vida voltada para a guerra. (Ends and Means, 1937). Os homens constroem tanques, bonbas atômicas, preocupam-se em se defender. Essa preocupação separa-os e os mantém oprimidos, temerosos, e voltados para uma atitude defensiva. Segundo Victoria Ocampo, Huxley disse-lhe logo após o término da Segunda Guerra Mundial, em 1945: "Tnank God we are to have peace very soon. But I confess that I find a peace with atomic bombs hanging overhead a rather disquieting prospect." (Julian Huxley, op. cit., p. 80)

O cientista ajuda o político a manter as massas oprimidas e não pode encontrar a própria felicidade. Ele tem medo, e este temor é causado pela tecnologia e o avanço científico. A tecnologia age como faca de dois gumes quando melhora o padrão de vida do homem e the propicia também una morte mais violenta. Não há paz completa quando o medo paira sempre no ar. (Ape and Essence). "Fear of the war we don't want and you do everything we can to bling about." (Op. cit., p. 51-52) O cientista se sente culpado pelo "progresso" que mata e destrói. A ciência traz o conforto à vida moderna e torna o homem um escravo dele. (Antic Hay). Este conforto se transforma em um fim em si mesmo (Prover Studies). Ohomem de ciência não sabe viver como um ser humano comum. Faltam-lhe as qualidades normais de um individuo. Ele parece estar mais próximo dos irracionais, com quem se identifica durante os estudos feitos; ele parece interessar-se mais pelos estudos do que pelos seus semelhantes. Ele é egoísta e só vê um lado das coisas, ignorando as aspirações humanas.

Voltamos a lembrar Brave New World (1932) e o retrato de uma sociedade cientificamente controlada, onde a droga é usada sempre que a realidade é difícil de ser vivida. A ciência criou um homem condicionado a ser feliz, um homem que não tem doenças, que não envelhece e que não aprendeu a amar É a "abolição do livre arbítrio pelo condicionamento metódico." Huxley mostra os perigos que podem advir do uso da ciência a serviço da política e do poder.

Voltemos ao Huxley de 1925, que disse preferir ser Faraday a ser Shakespeare. E interessante observar que, não obstante a confessada preferência, ele não oferece tratamento condigno ao cientista inglês, no livro Ape and Essence. Michael Faraday aparece acorrentado e puxado por uma coleira pelos macacos, os novos donos do mundo. (p. 
27) Na mesma obra, ele faz ironia da capacidade da ciência, quando diz que ela pode tornar universal uma doença de cavalos (glanders), pouco conhecida entre os homens ( $p .32$ ); fala do lábio leporino (harelip) como um produto característico do progresso tecnológico (p. 83); ele até mesmo anuncia a morte, por suicídio, da ciência do século XX. (p. 40) Com todas estas opiniões e críticas à ciência, somos levados a crer que, para Huxley, apesar de toda a culpa que pesa sobre o homem das ciências, talvez ele seja ainda mais feliz que o sensível homem das artes. Mais que muitos autores, Huxley viveu intensamente a sua época e preocupou-se demasiadamente com as duas Grandes Guerras, onde a ciência e o progresso tecnológico foram marcantes. Ele, que acompanhou de perto as duas, pôde sentir a diferença da Segunda Guerra Mundial, quando o homem já estava melhor aparelhado para exercer uma maior violência. A Terceira Guerra, que ele criou em Ape and Essence, prova a veracidade da afirmação. O homem caminha para frente na tecnologia, na ciência, mas se torna um homem materializado, sofrendo um verdadeiro retrocesso nos seus costumes e religião.

Em Island e Literature and Science, suas últimas obras, publicadas em 1962 e 1963 respectivamente, parece que Huxley vê a ciência com melhores oihos, embora aincia se apresente meio cético. Em Island, por exemplo, ele diz que Pala, a ilha do Pacífico, não tem nenhuma necessidade de grandes pesquisas, indústrias, pesadas e competitivas, e munições para tins bélicos. A ilha pode prescindir da avançada tecnologia. A missão dos educadores é ensinar uma "ciência de relacionamento" (science ofse ht ra do li un sesehthtradodoliunse htralidort namento" (science of relationship), a ciência da vida (p. 218) Com a ciência da vida os indivíduos "aprendem a viver como seres humanos, em harmonia com o resío do mundo" O ensinoda ciência começa muito cedo; as crianças aprenciem as primeiras lições de ecologia, ao mesmo tempo, em que aprendem as quatro operações. Huxley continua fiel ao seu princípio de que a ciência deve ser usada para o bem da humanidade.

Vejamos alguns cientistas de Huxley, após termos feito considerações sobre como ele vê a ciência. Já tivemos oportunidade de analisar personagens como James Shearwater, o fisiólogo (Antic Hay), e Edward Tantamount, o biólogo (Point Counter Point), no trabalho que escrevemos sobre o elemento do absurdo nos seus quatro primeiros livros de ficção. A importância dessas personagens, no ponto de vista científico do autor, é muito grande; porém, não gostaria de repetir considerações feitas naquele trabalho, mas mostrar algumas outras personagens, também marcantes, de obras posteriores. 
Já falamos da sociedade cientificamente manipulada de Brave New World. Lá se destaca Mustapha Mond, o cientista, que é um dos dez controlaciores do mundo, coin suas leis absolutas. Ele tem "o poder de determinar o número de pessoas que nascerão naquela sociedade e que espécie de vida cada uma vai levar." Os "slogans" ouvidos durante o sono e o condicionamento ao estilo pavloviano amoldam os seres para a sepécie de vida desejada. Na mocidade, o cientista teve de optar entre o conformismo naquele mundo e a ciência no exílio de uma ilha distante. $O$ poder fascinou-o, e ele foi treinado para controlar o mundo científico de homens pré-fabricados. Mustapha preferiu o poder à liberdade e é, agora, um dos que escravizam o próximo, tal como já foi escravizado. No longo diálogo travado com John, o "Selvagem", a personagem introduzia para contrastar com o homem do novo mundo, Mustapha Mond revela que sacrificou a arte, a ciência e a religião pela "felicidade" conquistada. "O mundo moderno não precisa de Deus porque Ele é incompatível com a maquinaria e a medicina científica e a felicidade universal" (Brave New World, p. 180-183) A droga "soma" representa calma, moralidade, paz, felicidade, religião, estabilidade social, e está engarrafada e ao alcance de todos. (p. 185) Para Mond, a "civilização", o modernismo justificavam tudo. A ciência e o conforto fizeram dele um ser automatizado. Mond difere, pois, dois outros cientistas de Huxley, porque ele punha a ciência a serviço do poder e da política, e vivia, exatamente, de acordo com os códigos e padrões vigentes, que divergiam completamente dos existentes no mundo de John, chamado o Selvagem. Agia de acordo com as conveniências.

Mustapha Mond se enquadra bem entre os "mesomorph somatotonic", se usarmos a classificação de Sheldon, tão apreciada por Huxley. Ele é o homem de olhar profundo e uma voz de "trombeta", com um forte poder de persuasão. É o extrovertido homem de ação, que controla a vida dos outros. Em uin trecho da obra, em que ataca a "horrível vida em família", pinta um quadro tão negro, que um dos estudantes quase passa mal do estômago. (p. 40).

Esta figura estranha defende com ardor os princípios vigentes no Mundo Novo, onde os homens das letras não são importantes; mas ele tem, paradoxalmente, acesso a obras de inúmeros autores, que traz adverte quanto aos perigos da ciência, que deve ser controlada ( $p$. trancadas em um cofre de sua sala. Mond, que já foi um grande físico, 177) Numa atitude paradioxal acrescenta que a ciência é um livro de receitas, e ele é agora, o mestre-cuca. ( "all our science is just a cookery book, I'm the head cook now", p. 177)

Peter Boone é o jovem cientista de After Many a Summer. Como vários outros cientistas de Huxley, ele parece um ingênuo e, embora se 
dedique com afinco aos estudos de como prolongar a vida alheia, não consegue ter a sua muito longa. E morto por um crime que não cometeu e, numa ironia, é vítima de um engano, pagando pelo pecado cometido por outros. E assassinado por Jo Stoyte, o magnata americano, que, num momento de grande ciúme da sua garota Virginia, atira no homem que julga ser seu rival. Pete ama Virginia, realmente, mas não sabe como conquistá-la, pois não tem a mesma iniciativa no amor que tem na busca científica, de que é também um apaixonado.

Pela descrição da personagem e julgamento de outras, vemos que é um jovem romântico, simples, sensível, mas que vive fora da realidade. Ele nem percebe que Virginia flerta com ele em público, para proteger Obispo, que é, realmente, quem lhe interessa. A atitude de Virginia está muito além de sua compreensão.

Sigmund Obispo, o médico de Jo, que comanda as experiências sobre longevidade, é o verdadeiro amante de Virginia. Ele é corrupto, hipócrita e aproveita de sua função de médico, para viver uma vida de hedonismo na mansão da Califórnia. Ele se vangloria de seus conhecimentos literários e científicos, que lhe permitem ter acesso ao quarto de Virginia, sob o pretexto de ler francês para ela, e livrar-se de Jo, dando-lhe doses de barbitúricos para fazê-lo alheio ao que se passa ao redor. Enquanto Jo dorme sob o efeito da droga, Obispo ama Virginia tranqüilamente. Mas mesmo que Jo apareça no quarto e os pegue juntos, Obispo sabe como recorrer à medicina para salvar a própria pele $\mathrm{O}$ estetoscópio, que traz no bolso, prova a sua estada ali à espera do milionário para auscultar seu peito e costas. Jo Stoyte the é até muito grato por "tamanha preocupação"

Pete e Obispo são dois tipos contrastantes. O primeiro é muito ingênuo, e o segundo é pervertido. Pete paga com a vida a sua ingenuidade, e Obispo e Virginia são poupados porque sabem como enganar Jo. Não é fácil confessar a culpa e arriscar-se a perder a vida de prazeres na mansão hollywoodiana. Depois que Pete morre, Obispo domina Jo completamente, porque ele possui o segredo do assassinato, que faz com que Jo Stoyte seja um verdadeiro joquete em suas mãos. O atestado de óbito de Pete, constando "morte repentina devido a um problema cardíaco", rendeu-lhe o emprego vitalicio de médico de Jo, que agora tem problemas de insônia e pavor da polícia.

A ciência é aqui aplicada para que um homem tenha uma longa vida, vida esta que já fora inútil e dedicada aos prazeres sensuais e que, mais tarde, será semelhante à de um macaco. Sim, porque as experiências provaram que o homem poderá ter a vida alongada, mas se tornará uma espécie de macaco, gozando apenas da satisfação sexual. O que 
a ciência faz é uma volta no tempo, porque o homem regride como ser humano e age animalescamente, na sua sexualidade.

Pete poderia ser classificado entre os "ectomorph cerebrotonic" E fraco, indeciso, incapaz até mesmo de declarar seu amor a Virginia. Vivendo muito mais o mundo interior de seu quarto escuro, não é capaz de compreender a vida. Obispo seria o "mesomorph somatotonic" Cínico, hipócrita, vive uma vida de ação e perigo, em constante risco de ser pego com Virginia. Conhecedor do crime de Jo e de como fazê-lo viver mais, manobra a vida do milionário como bem entende.

Em Ape and Essence (1949), a sociedade teme a vida moderna. Os padrões de vida são superiores graças à ciência, mas o homem tem medo do que lhe possa acontecer. ("Fear of the science which takes away with one hand even more than what it so profusely gives with the other." (p. 38) Após uma Guerra Atômica (o efeito do "progresso"), os homens exibem uma religião às avessas. Deus é substituído por "Belial", um ser diabólico, e a degradação impera. Um grupo de cientistas veio da Nova Zelândia, único local que escapou da devastação da bomba atômica. Dr. Alfred Poole é o botânico que se perdeu dos companheiros e que, por ter conhecimentos científicos, é poupado porque deve ensinar aos habitantes daquelas terras assoladas pelas bombas, como produzir alimentos. O mundo foi destruído do modo mais avançodo, e agora falta o que é básico para sobreviver. Os povos alcançaram o conhecimento máximo para destruir, mas não sabem como construir A morte desafia a vida, e os mortos são perturbados no seu repouso, nos cemitérios, para fornecer aos vivos objetos de que eles necessitam e não têm mais à mão.

Dr. Poole, que seria o "herói" do livro, é na verdade um "antiherói" E medroso, indeciso, e apegado à mãe. O excessivo amor materno fê-lo permanecer solteiro até os trinta e oito anos. Não há meiotermo na vida de Poole. Ele vive extremos: de inibido, tímido, preso a convenções e ao respeito à mãe, passa a total depravado.

Huxley retrata de modo desfavorável esta personagem que encontra o amor em Loola, uma jovem de dezoito anos, que está sofrendo as consequiências de Guerra Atômicá. Fogem juntos daquele local, que a ciência transformou em um verdadeiro inferno, para sobreviverem.

Dr Poole poderia ser classificado como um "ectomorph cerebrotonic", a princípio. E fraco, dependente e dedicado à ciência, mas ele "evolui" (ou regride?) sob a influência de Loola e da sociedade californiana. Na luta pela sobrevivência e na busca da companhia da mulher 
amada, ele exibe um comportamento não muito esperado de um "cerebrotonic", ao final.

Em The Genius and the Goddess (1955) o gênio é o físico Henry Maartens, marido da deusa Katy. Henry é uma estranha personalidade, que precisa do estímulo da esposa para viver. Não é capaz de enfrentar a vida sozinho. Quando ela fica longa temporada fora de casa, tratando da mãe doente, Henry por pouco não encontra a morte. Katy, por sua vez, busca em Jonh Rivers, um jovem físico assistente do marido, o carinho que este não lhe dá. Possuída do amor físico, ela tem forças para ajudar o esposo. Henry está por demais envolvido com os estudos científicos, que até lhe granjearam o Prêmio Nobel, para ver o que se passa a seu redor. Emocionado é uma criança que se deixa trair pelo assistente e a esposa. O gênio precisa da deusa para revitalizá-lo, e ela "cchou o caminho para o olimpo na sensualidade" (P 107) Existe aí o famoso triângulo amoroso - dois cientistas, um dos quais um gênio", — e uma "deusa" Assim são os cientistas huxleyanos. Nada têm de admirável quando fora de seus laboratórios, afastados das pesquisas e experiências. São quase sempre traídos pelas esposas, que não podem compartilhar os interesses científicos dos maridos porque, em geral, são muito "mundanas" para viver no plano da ciência. Os maridos estão muito preocupados com os estudos científicos, e não sabem conciliar as coisas.

Os cientistas ficariam entre os "ectomorph cerebrotonic", pois ambos são fracos, cada qual a seu modo. O traído não tem a faculdade de perceber as coisas e o traidor tem enormes conflitos interiores.

Das obras de Huxley se conclui que ninguém pode se dedicar exclusivamente à ciência ou à arte: é preciso ter um meio-termo. Ninguém pode viver uma vida unilateral, ignorando outros aspectos importante. O instinto é necessário aos que exercitam a mente; e o ser humano, para merecer ser assim chamado, seja ele um cientista ou um literato, precisa saber pensar, sentir, amar; precisa entender que há uma diversidade humana, que deve ser respeitada.

O homem não pode ser um robĉ condicinnado ou um indivíduo extremado. Um ser humano ideal talvez seja um misto de Faraday e Shakespeare.

\section{BIBLIOGRAFIA}

BEDFORD, Sybille. Aldous Huxley. A Biography. London, Chatto \& Windus in Association with Collins, 1973. 
BEDFORD, S. Aldous Huxley. A Biography, 1939-1963. London, Chatto \& Windus in Association with Collins, 1974.

BIRNBAUM, Milton. Aldous Huxley's Quest for Values. U.S.A., The University of Tennessee Press, 1971.

CARVAlHo, Alfredo Leme Coelho. A Fiç̧āo Dispópica de Huxley e Orwell. São José do Rio Preto, Estudos Anglo-Hispynicos n.o s 2-3, F.F.C.L., 1969-1970.

HUXLEY, Aldous. Crome Yellow. London, Penguin Books in Association with Chatto \& Windus, 1971.

HUXLEY, A. Antic Hay. England, Penguin Books in Association with Chatto \& Windus, 1971.

HUXLEY, A.. Those Barren Leaves. London, Penguin Books in Association with Chatto \& Windus, 1967

HUXLEY, A. Point Counter Point. Great Britain, Penguin Books in Association with Chatto \& Windus, 1955.

HUXLEY, A. Brave New World. England, Penguin Books in Association with Chatto \& Windus, 1972.

HULEY, A. Eyeless in Gaza. Great Britain, Penguin Books in Association with Chatto \& Windus, 1971.

HUXLEY, A. After Many a Summer London, Penguin Books, 1961.

HUXLEY, A. Time Must Have a Stop. New York, Harper \& Row Publishers, 1965.

HUXLEY, A.. Ape and $n$ Essence. New York, Hasper \& Row Publishers, 1972.

HUXLEY, A. The Genius and the Goddess. U.S.A.. Bantam Books, Inc. 1969. HUXLEY, A.. Island. London, Penguin Books, 1971.

HUXLEY, A. Brave New World Revisited. New York, Harper \& Row Publishers, 1965.

HUXLEY, A. Along the Road: Notes \& Essays of a Tourist. London, Chatto \& Windus, 1925.

HUXLEY, A.. On Art and Artists. London, Chatto \& Windus, 1960.

HUXLEY, A. Ends and Means. London, Chatto \& Windus, 1938.

HUXLEY, A. On the Margin. London, Chatto \& Windus, 1947

HUXLEY. A. The Olive Tree. London, Chatto \& Windus, 1947

HUXLEY, A.. Texts and Pretexts. London, Chatto \& Windus, 1974.

HuXLEY, A. The Perennial Philosophy. London, Harper \& Brothers, 1945.

HUXLEY, A. Jesting Pilate. New York, George H. Doran Co., 1926.

HUXLEY, A. Science, Liberty and Peace. London, Chatto \& Windus, 1947.

HUXLEY, A. Proper Studies. London, Chatto \& Windus, 1927.

HUXLEY, A. Literature and Science. New York, Harper \& Row, 1963.

HUXLEY, Julian. (ed.) Aldous Huxley. 1894-1963. A Memorial Volume.

London, Chatto \& Windus, 1966.

HUXLEY, Julian. Memories II. London, George Allen and Unwin Ltd., 1973.

SWIFT, Jonathan. Gulliver's Travels. London, Collins, 1953. 